\title{
Relation between retinal vein occlusions and axial length
}

\author{
Nurşen Aritürk, Ýhsan Öge, Dilek Erkan, Ýüksel Süllü, Farshid Mohajerý
}

\begin{abstract}
Aims-To evaluate the ocular axial length as a risk factor for development of central retinal vein occlusion (CRVO) and branch retinal vein occlusion (BRVO).

Methods-Ocular axial lengths were measured, by A-scan ultrasonography, in 17 patients with CRVO and 41 patients with BRVO and compared with those of contralateral unaffected eyes and 66 age matched controls.

Results-In 17 patients with CRVO the mean axial length of affected eyes was 22.25 (SD 0.19) $\mathrm{mm}$ and of unaffected eyes was $22.61(0.13) \mathrm{mm}$. In 41 patients with BRVO the mean axial length of affected eyes was $22.89(0.11) \mathrm{mm}$ and of unaffected eyes was $22.99(0.12) \mathrm{mm}$.

Conclusion-These findings confirm that the axial lengths in CRVO and BRVO were significantly shorter than in the controls. This significant difference may be a risk factor in the development of CRVO and BRVO.

(Br F Ophthalmol 1996;80:633-636)
\end{abstract}

Retinal vein occlusion is the second most common retinal vasculopathy, after diabetic retinopathy, which results in permanent visual loss. After so many years of investigation, its exact aetiopathogenesis has still not been clarified. However, we do know that there are a variety of factors that can disturb ocular circulation and so cause retinal vein occlusion.

Histopathological studies on both central retinal vein occlusion (CRVO) and branch retinal vein occlusion (BRVO) have revealed that local factors such as physical blockage secondary to compression, and systemic factors, which may result in haemodynamic changes and occlusion of blood flow, together can contribute to thrombus formation. ${ }^{1}$ Green $e t a l$, in a histopathological study on 29 enucleated eyes with CRVO, have documented that thrombus forms at or near the lamina cribrosa region. ${ }^{2}$ Also, Frangieh and colleagues, in a histopathological study, showed that in BRVO the site of occlusion is almost invariably arteriovenous junctions, where it is caused by thrombus formation in the venous system secondary to capillary and arteriolar changes. ${ }^{3}$ It has been postulated that eyes with shorter axial length have smaller lamina cribrosa and a narrower scleral canal through which the central retinal vein and artery could pass, causing physical blockage in the vein which predisposes to thrombus formation. ${ }^{45}$

We studied this mechanism in CRVO, and at the same time the underlying pathogenesis of the BRVO was investigated.

\section{Materials and methods}

Seventeen patients with CRVO and 41 patients with BRVO who were admitted to our ophthalmic centre between November 1994 and May 1995 were studied.

All 58 patients underwent systemic and ocular examination. Systemic examination included fasting blood sugar level, blood lipid level and coagulation factors; systemic blood pressure measurement with cardiovascular examination; and diabetes mellitus, blood hyperviscosity syndromes, and systemic arterial hypertension. Ophthalmic examination included intraocular pressure measurement, direct and indirect ophthalmoscopy; gonioscopy and fundus fluorescein angiography. Aphakia, pseudophakia, corneal leucoma, retinal detachment, and other intraocular mass lesions, which could interfere with accurate axial length measurement, were excluded.

Ocular axial lengths were measured by A-scan ultrasonography (Nidek Echoscan US3300 ) with a sound velocity of $1550 \mathrm{~m} / \mathrm{s}$, and six consecutive measurements were done by the manual direct contact technique. Patients were instructed to fixate on a small red light within the centre of the probe tip and high quality, consistent measurements were taken as optimum axial length values. All measurements were done by the same person to minimise errors.

The randomly selected control subjects consisted of 66 age matched patients with no retinal vein obstruction and no refraction default. Axial lengths were measured by the same person using the same technique.

In patients with retinal vein occlusion the axial length of the affected eyes were compared with the other healthy unaffected eyes, and also with the control eyes. Statistical analyses were performed by paired $t$ and Student's $t$ tests. Statistical significance was considered as $p<0.05$. The means were given with their standard error (SEM) and difference between the two means were compared within the $95 \%$ confidence interval.

\section{Results}

Of the 17 patients with CRVO, 11 were women and six were men. Their ages ranged between 55 and 73 years with a mean of 63.87 (SEM 
Table 1 Distribution of cases according to age and sex

\begin{tabular}{lllllll}
\hline & \multicolumn{3}{l}{ Age } & & \multicolumn{2}{l}{ Sex } \\
\cline { 2 - 3 } \cline { 5 - 6 } Cases of retinal vein occlusions & Mean & SEM & & Female & Male \\
\hline Central occlusions & 63.87 & 2.68 & & 11 & 6 \\
Branch occlusions & 59.33 & 0.96 & & 27 & 14 \\
Control group & 62.77 & 1.31 & & 38 & 28 \\
p Value & $>0.05$ & & & & \\
\hline
\end{tabular}

2.68) (Table 1). All patients were affected uniocularly, eight affected in the right eye and nine in the left eye.

Of the patients in the CRVO group, 11 had hypertension $(64.70 \%)$, four had diabetes mellitus $(23.52 \%)$, three had both diabetes mellitus and hypertension (17.64\%), and two of them had glaucoma $(11.76 \%)$. Three patients had hypermetropic spectacles, ranging from +0.50 to $+1.50 \mathrm{D}$. The mean axial length of the affected eyes was $22.25(0.19) \mathrm{mm}$ (range 21.17-4.41 $\mathrm{mm}$ ) and of the other unaffected eyes was 22.61 (0.13) $\mathrm{mm}$ (range $21.84-3.20 \mathrm{~mm}$ ).

Of the 41 patients with BRVO 14 were men and 27 were women, with a mean age of 59.33 (0.96) years, ranging between 45 and 72 years. Twelve patients $(29.26 \%)$ were affected in the left and 29 patients $(70.73 \%)$ in the right eyes, and three patients in both eyes. In 30 eyes $(73.17 \%)$ the superior temporal, in 13 eyes $(31.70 \%)$ the inferior temporal, and in one eye $(2.4 \%)$ the inferior nasal region was involved. The obstruction was generally near the optic nerve in the arteriovenous junction zone. In four patients with BRVO we observed CRVO within 3-4 months of follow up.

Of the BRVO group, 26 patients $(63.41 \%)$ had hypertension, five patients $(12.19 \%)$ had diabetes mellitus, two patients $(4.8 \%)$ had glaucoma, five patients $(12.19 \%)$ had both hypertension and diabetes mellitus, and seven of them $(17.07 \%)$ had hyperlipidaemia with arteriosclerosis. Eight patients had spectacles with prescriptions ranging between +0.50 and +1.50 . In this group (BRVO) the mean ocular axial length in involved eyes was 22.89 (0.11) $\mathrm{mm}$ (range $22.03-24.63 \mathrm{~mm}$ ) and that of the unaffected eyes was $22.99(0.12) \mathrm{mm}$ (range 22.04-24.72 mm). Bilateral occlusions were excluded.

The control group included 66 people, 28 men and 38 women, in whom the mean age was 62.77 (1.31) (range 49-75) years. The mean axial length of the control group was $23.22(0.09 \mathrm{~mm})$ (range 22.31-25.1 $9 \mathrm{~mm}$ ).

In the CRVO group the difference between the mean axial length of involved eyes and uninvolved eyes (mean difference $0.36 \mathrm{~mm}$ ) was statistically significant $(p<0.05,95 \%$ confidence interval $-0.62 ;-0.09)$. The mean difference between the affected eyes and control eyes $(0.97 \mathrm{~mm})$ was also statistically significant $(\mathrm{p}<0.001,95 \% \mathrm{CI}-1.26 ;-0.40)$. This significant difference between the affected eyes and contralateral unaffected eyes is because of the effect of macular oedema on the ocular axial length measurements (Table 2). The mean axial length of uninvolved eyes of patients with CRVO was significantly shorter $(0.61 \mathrm{~mm})$ than that of the control group ( $p<0.01,95 \% \mathrm{CI}-1.05 ;-0.17)$. Thus we concluded that the short axial lengths in the affected eyes were not the consequence of the effect of macular oedema.

In the BRVO group, the difference between the mean ocular axial lengths of the involved eyes and contralateral unaffected eyes $(0.14$ $\mathrm{mm})$ was not statistically significant $(\mathrm{p}>0.05)$. But the difference between the control eyes and affected eyes $(0.33 \mathrm{~mm})$ was statistically significant $(p<0.05,95 \%$ CI $-0.63 ;-0.04)$ ) (Table 3).

\section{Discussion}

As mentioned above there are so many risk factors for RVO including hypertension, diabetes mellitus, arteriosclerosis, primary open angle glaucoma, hyperlipidaemia, hyperviscosity, increase in fibrinogen and coagulation factors, and deficiencies in proteins $\mathrm{C}$ and $\mathrm{S}^{6-8}$ Hayreh et al have observed that the most prevalent ages for CRVO development are 65

Table 2 Comparison of axial length in central retinal vein occlusion with both unaffected and control eyes

\begin{tabular}{llllll}
\hline & \multicolumn{2}{l}{ Axial length measurments } & & \\
\cline { 2 - 5 } & \multicolumn{1}{c}{ Affected eyes } & & \multicolumn{2}{c}{ Unaffected eyes } & pValues * \\
\hline $\begin{array}{l}\text { Central vein occlusion } \\
(\mathrm{n}=17)\end{array}$ & 22.25 & $(0.19)$ & 22.61 & $(0.13)$ & $<0.05(0.36,-0.62 ;-0.09)$ \\
$\begin{array}{c}\text { Control group } \\
(\mathrm{n}=66)\end{array}$ & 23.22 & $(0.09)$ & 23.22 & $(0.09)$ & - \\
$\mathrm{p}$ Valuest & $<0.001$ & $<0.01$ & & \\
& $(0.97,-1.26 ;-0.40)$ & $(0.61,-1.05 ;-0.17)$ & & & \\
\hline
\end{tabular}

$\star$ Paired $t$ test (mean difference, $95 \%$ confidence interval).

†Student's $t$ test (mean difference, $95 \%$ confidence interval).

Table 3 Comparison of axial length in branch retinal vein occlusion with both unaffected and control eyes

\begin{tabular}{llllll}
\hline & \multicolumn{2}{l}{ Axial length measurement } \\
\cline { 2 - 5 } & Affected eyes & & Unaffected eyes & pValue* \\
\hline Branch vein occlusions ( $=41)$ & 22.89 & $(0.11)$ & 22.99 & $(0.12)$ & $>0.05$ \\
Control group ( $=66)$ & 23.22 & $(0.09)$ & 23.22 & $(0.09)$ & \\
p Valuet & $<0.05(-0.33,-0.63 ;-0.04)$ & & $>0.05(0.23)$ & & \\
\hline
\end{tabular}

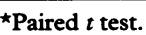

†Student's $t$ test (mean difference, 95\% confidence interval). 
years and older, and it is more common in men than women, and more predominant in right eyes than left; however, BRVO is more common in women. ${ }^{9}$ Gutman reported that $90 \%$ of retinal vein obstructions occur in the 50 year age group or older. ${ }^{10}$ In our study $95.6 \%$ of patients were older than 50 , and retinal vein obstructions were more common in the right eyes.

In retinal vein obstruction, hypertension and diabetes mellitus prevalence were found to be $52.9 \%$ and $14.6 \%$ by Yazar $e t$ al, ${ }^{11}$ and $57 \%$ and $14.6 \%$ by Magargal, ${ }^{12}$ respectively. The prevalence of primary open angle glaucoma was found to be $32 \%$ by Magargal ${ }^{12}$ and $23 \%$ by Hayreh. ${ }^{13}$ In our study $63.79 \%$ of patients had hypertension, $15.51 \%$ diabetes mellitus, and $6.8 \%$ had glaucoma; these results correspond with reports in the literature.

When we evaluate retinal circulation using rheology, the science of deformation and flow of matter, we see that the retina and choroid have a relatively high blood flow rate for their tissue mass. Also, retinal veins in arteriovenous junctions and in the scleral canal can be compressed by arteries and lamina cribrosa respectively. Because of this, retinal vascular structures are different from other vascular structure. Furthermore, high metabolic requirements of the retina are prone to the effects of blood flow changes. ${ }^{6}$ The pathogenesis of thrombus formation is a multifactorial process In a histopathological evaluation of eyes affected with CRVO, a thrombus was demonstrated at or near the lamina cribrosa. ${ }^{2}{ }^{14}$ There are some anatomical factors predisposing to this localisation including the common adventitial sheath that surrounds CRV and CRA within the optic nerve. ${ }^{1}$ The sieve-like structure of the lamina cribrosa which is formed from interweaving fascicles of collagen bundles with no elasticity, restricts the expansion of the vessels passing through it. There is an increased prevalence of arteriosclerotic disease in patients with CRVO. ${ }^{15}$ Arteriosclerotic changes affect the media and intima, and the involved arteries become more rigid with narrowed lumen and scleral canal. Green and coworkers were able to demonstrate histopathologically a thrombus in the CRV at or near the lamina cribrosa in each of 29 enucleated eyes with CRVO. They hypothesised that within the lamina cribrosa, the vessel is in close proximity to the central retinal artery and a thickened artery in this region can impinge upon the vein and lead to turbulent blood flow in that vein, with subsequent endothelial damage, platelet aggregation, and thrombus formation. ${ }^{16}$

It has been reported that incidence at hypermetropia is higher in CRVO and BRVO than in the normal population. ${ }^{10}$ In axial hypermetropia the ocular axial length is short secondary to the shorter axial length, the scleral canal is smaller, and the lamina cribrosa fenestrations are narrow. This creates crowding at the nerve fibres and CRV and CRA in the optic canal. In eyes with no hypermetropia the relation between the short ocular axial length and scleral canal crowding is the same. In the CRVO group the mean ocular axial length was
$0.97 \mathrm{~mm}$ shorter than in control eyes. This difference was statistically significant $(p<0.01)$. Also the difference between the mean axial length of affected eyes and the contralateral unaffected eyes was significant $(p<0.05)$. We believe that this difference could be due to the effect of macular oedema in the involved eyes. In a comparison between the unaffected eyes and the control eyes the axial lengths of the contralateral unaffected eyes were significantly shorter than in control eyes $(p<0.01)$. This finding reveals that the short axial lengths were not only the result of macular oedema. During measurement of axial length, excessive pressure on the cornea by an ultrasound probe or the deviation of ultrasound waves to the periphery of the macula may result in false values because of oedema in retina and optic nerve. ${ }^{17}$ In this study the same experienced person performed the axial length measurements in order to minimise this probability. Kumar et al, ${ }^{18}$ Brown et $a l,{ }^{7}$ and Gözüpýnar et $a l^{19}$ have shown that, in eyes with CRVO, axial length is shorter than in control eyes, but no significant difference was found between affected eyes and contralateral unaffected eyes.

BRVO has a better visual outcome than CRVO but its underlying aetiopathogenesis is similar to CRVO. ${ }^{1}$ According to anatomical, histopathological, and fundus fluorescein angiography studies, BRVO generally occurs at arteriovenous junctions; arteries and veins share common adventitial sheath at these sites. ${ }^{1}$ Frangieh et al in a histopathological study observed that in BRVO venous thrombosis is secondary to capillary and arterial changes. ${ }^{3}$ The pathophysiological significance of arteriovenous junctions in BRVO is not yet clearly understood. In normal eyes $70-75 \%$ are arteriovenous junctions. In 1877 Leber observed that BRVO occurs at arteriovenous junctions. ${ }^{5}$ It has long been known that BRVO occurs most commonly in the superotemporal region $^{1}$; it is reported that there was a relation between the BRVO and anatomical factor of this region, because arteriovenous junctions occur mostly at the superior temporal quadrant of the retina. ${ }^{520}$ In our study of BRVO $74.35 \%$ of cases involved the superotemporal region. Weinberg et al observed that $97.6 \%$ of obstructions occur at arteriovenous junctions $^{20}$; Feist et $a l^{5}$ reported $93 \%$ and Safak et $a^{21} 79 \%$. Arteriosclerosis causes stenosis of both the artery and vein, decreasing the arterial perfusion pressure which leads to venous stasis; the changes in the vessel endothelium cause platelet aggregation and that leads to thrombus formation. Hypermetropia is a risk factor in BRVO, as in CRVO. ${ }^{10}$ In our study, axial lengths were measured in cases of BRVO without hypermetropia and the difference between the mean of ocular axial lengths of the affected eyes and the control eyes $(0.33 \mathrm{~mm})$ was statistically significant $(p<0.05)$. Although Gözüpýnar et $a l^{19}$ reported that short axial length was not a significant factor, we believe that short axial length may be a predisposing factor in the development of BRVO. Multiple systemic and local factors gradually progress, affecting the ocular vasculature and eventually 
result in retinal venous obstruction. In our opinion the short axial length, which results in a smaller scleral canal and scleral crowding, impedes venous drainage of the retinal vasculature to some degree when the adjacent artery is sclerotic. This phenomenon causes a decrease in ocular blood flow rate and venous stasis.

We also believe that BRVO can be an early sign of development of CRVO, as in our study, four cases of BRVO (10.3\%) developed CRVO within 3-4 months of follow up. Finally, we suggest that short axial length can predispose not only to CRVO, but also to BRVO.

1 Sanborn, GE, Magargal, LE, Jarger EA. Venous occlusive dis ease of the retina. Clinical ophthalmology. Vol 3, Chapter 15. ease of the retina. Clinical ophthalmolog

2 Green WR, Chan CC, Hutchins GM. Central retinal vein occlusion: a prospective histopathologic study of 29 eyes in 28 cases. Retina 1981;1:27-55.

3 Frangieh GT, Green WR, Barraquer-Somers E, Finkelstein D. Histopathologic study of nine branch retinal vein occlusions. Arch Ophthalmol 1982;100:1132-5.

4 Gutman, AF. Central retinal vein occlusion. Chibret Int $\mathcal{f}$ Ophthal (suppl) 1990;93:101.

5 Feist RM, Ticho BH, Shapiro MJ, Farber PH. Branch retinal vein occlusion and quantitative variations in arterional vein occlusion and quantitative variations in
venous crossing. Am $₹$ Ophthalmol 1992;13:664-8.

6 Şener C, Özdemir O, Oruç S, Eldem B, Kirazlý Ş. Retina Şener C, Ozdemir O, Oruç S, Eldem B, Kirazly Ş. Retina
ven týkanýklýgýna eşlik eden antikoagülan ve fibrinolitik faktör eksiklikleri: protein $\mathrm{C}$ vs protein S. Türk Oft $G a z$ 1992;22:371-5.

7 Brown MM, Brown CG, Menduke H. Central retinal vein obstruction and axial length. Ophthalmic Surg 1990;21 623-4.
8 Grath MA, Wechsler F, Hunyor ABL, Penny R. Systemic factors contributing to retinal vein occlusion. Arch Intern Med 1978;138:216-20.

9 Hayreh SS, Zimmerman B, Pohajsky P. Incidence of various types of retinal vein occlusion and their recurrence and demographic characteristics. Am f Ophthalmol 1994;117: 429-41.

10 Gutman FA. Evaluation of a patient with central retinal vein occlusion. Ophthalmology 1990;90:481-3.

11 Yazar Z, Nurözler A, Duman S. Santral retinal ven okluzyonlu olgularýn değerlendirilmesi. Türk Oft Gaz 1993;23:336-40.

12 Magargal L, Brown G, Augsburger J, Parrish R. Neovascular glaucoma following central retinal vein obstruction. Ophthalmology 1981;88:1095-101.

13 Hayreh SS, Rogos P, Podhojsky P, Montaque P, Woolson R. Ocular neovascularisation with retinal vascular occlusionIII. Ophthalmology 1983;90:488-506.

14 Klein BA. Occlusion of the central retinal vein: clinical importance of certain histopathologic observations. $A m \mathcal{F}$ Ophthalmol 1953;36:316-9.

15 Paton AR, Rubinstein K, Smith VH. Arterial insufficiency in retinal venous occlusion. Trans Ophthalmol Soc UK 1965;84:559-63.

16 Green WR. Retinal ischemia vascular and circulatory conditions and diseases. In Spensor WH, ed. Ophthalmic pathology: an atlas and textbook. Vol 2. Philadelphia: WB Saunders, 1985:655-709.

17 Byrne SF, Green RL. Ultrasound of the eye and orbit. St Louis: Mosby Year Book, 1992:215-42.

18 Kumar A, Ahuja S, Tewari HK, Khosla PK, Azad RV. Short axial length: risk factor for central retinal vein occlusion. Ann Ophthalmol Glaucoma 1994;26:145-7.

19 Gözpýnar Ö, Topbas S, Başmak H, Erol N,Yurdakul S Retinal ven týkanýklýklarý ve aksiyel uzunluk. XXV11. Ulusal Kongre veYaz Sempozyumu Özet Kitabý 1993:120.

20 Weinberg D, Dodwell DG, Fern JA. Anatomy of arteriovenous crossings in branch retinal vein occlusion. $A m \mathcal{J}$ Ophthalmol 1990;109:298-303.

21 Şafak N, Karabaş LV, Sendilek B, Günal K, Erbil HH. Retina ven dal týkanýklýǵý olgularýnda arter-ven çaprazlasmalarýnýn seyrí, kadransal dağýlým ve göreceli pozisyonlarýn incelenmesi. XXVIll. Ulusal Kongre Bülteni Cilt 2, 1994(Suppl): 625-6. 